ÁREA ABIERTA. Vol.13. $n^{\circ} 1$. Marzo 2013.

http://dx.doi.org/10.5209/rev_ARAB.2013.v34.n1.41590

Referencia: AA34.1303.173

"FANTASÍA SUBURBANA EN EL CINE DE M. NIGHT SHYAMALAN:

LA HUELLA CREATIVA DE STEVEN SPIELBERG"

AUTOR: Dr. Antonio SÁNCHEZ-ESCALONILLA

Universidad Rey Juan Carlos

\title{
Fantasía suburbana en el cine de M. Night Shyamalan: la huella creativa de Steven Spielberg
}

\author{
Suburban Fantasy in M. Night \\ Shyamalan Films: The Creative \\ Trace of Steven Spielberg
}




\section{RESUMEN:}

La obra del director y guionista Manoj Night Shyamalan supone una aportación decisiva para la consolidación del género de fantasía de aventuras dentro del ámbito cinematográfico. El director se ha caracterizado por el uso de un patrón dramático donde la exploración adecuada del ámbito ordinario de las aventuras revela, por un lado, una dimensión transida por lo maravilloso y, por otro, un redescubrimiento de la identidad de los personajes. En el presente artículo se estudian los universos diegéticos construidos por Shyamalan en cuatro de sus guiones de fantasía de aventuras, en los que el director refleja sus convicciones personales de la vida desde la óptica de los cuentos de hadas. Un signo creativo donde se también advierte la influencia de Steven Spielberg, a quien Shyamalan toma como referencia en el inicio de su carrera.

\section{Palabras clave:}

M. Night Shyamalan, Fantasía de aventuras, Mundo ordinario, Estructura de guión, Construcción de personajes.

\section{ABSTRACT:}

The work of writer and director Manoj Night Shyamalan reveals a main contribution to the consolidation of adventure fantasy as a filmic genre. This director is characterized by the use of a master plot where the proper exploration of the ordinary in adventure reveals a world transfixed by the hidden wonderful dimension. And at a time, the explorer character rediscovers his/her identity. This article studies the narrative universes created by Shyamalan in his four main fantasy adventure screenplays, where the director reflects personal convictions about life from the perspective of fairy tales. This is also a creative sign that can be perceived as an influence from Steven Spielberg, an acknowledged reference to Shyamalan at the beginning of his career.

\section{Key words:}

M. Night Shyamalan, Adventure Fantasy, Ordinary World, Screenplay Structure, Characters Building 


\section{Base introductoria o por qué estudiar "Lost"}

El presente trabajo pretende analizar y valorar las aportaciones de M. Night Shyamalan a la consolidación de la fantasía de aventuras dentro del ámbito cinematográfico. Concretamente, este estudio aborda la obra fantástica del director a través de cuatro producciones escritas y realizadas entre 1999 y 2005. Pero para ello es preciso, como premisa inicial, la concreción del enfoque fantástico empleado en este análisis, la definición del propio género híbrido y la consideración de sus núcleos esenciales.

A continuación, se señalará la influencia de un director perteneciente a una generación previa, Steven Spielberg, manifestada a través de diversos lugares comunes que podrían reunirse bajo la etiqueta de fantasía suburbana. Tras estas consideraciones preliminares, se abordará el estudio de las cuatro aportaciones fantásticas fundamentales del director entre 1999 y 2005 -"El sexto sentido" (1999), "El protegido" (2001), "Señales" (2002) y "La joven del agua" (2005)-, según los rasgos constitutivos de la fantasía de aventuras y las peculiaridades específicas de la fantasía suburbana.

Como conclusión, se expondrán de manera sintética las notas creativas características que Shyamalan aporta a la fantasía de aventuras y que han contribuido a su mencionada consolidación como género cinematográfico, ya sucedida en el ámbito literario durante el primer cuarto del siglo XX.

\section{La exploración de lo maravilloso: fantasía de aventuras en mundos ordinarios}

En cuanto género híbrido, la fantasía de aventuras surge de la fusión de los núcleos esenciales aportados por dos géneros canónicos afluentes. Por un lado, la exploración del universo por parte de la aventura, y la experiencia de lo maravilloso por parte de la fantasía. Tomando estos núcleos como referencia, la definición de fantasía de aventuras podría sintetizarse como la aventura protagonizada por héroes que comparten la experiencia ordinaria de lectores o espectadores y que, mientras acometen una misión, llevan a cabo un viaje de exploración en un mundo secundario de fantasía, o bien experimentan un encuentro con seres fantásticos, al tiempo que perciben lo maravilloso como extraordinario'.

En esta concepción del género resultante, la entidad de la aventura no ofrece interpretación o equivocidad algunas, pues el concepto remite a una trama física de exploración de espacios ignotos, al peligro inherente al propio viaje, a las subtramas de

\footnotetext{
${ }^{1}$ La propuesta de fantasía de aventuras como género híbrido puede consultarse en Sánchez-Escalonilla, A. "Fantasía de aventuras: La exploración de universos fantásticos en literatura y cine", Comunicación y Sociedad, vol. XXII, n. 2, 2009, pp. 109-137. Un estudio más profundo sobre el tema puede encontrarse en Sánchez-Escalonilla, A. Fantasía de aventuras. Claves creativas en novela y cine, Barcelona: Ariel, 2009.
} 
amistad y a una exploración interior a menudo combinada con tramas mentales de descubrimiento, madurez y sacrificio. En cambio, el género afluente de fantasía resulta más complejo de considerar debido a sus distintas concepciones. Entre todas ellas, destacan las propuestas por Tzvetan Todorov y por Maria Nikolajeva, sustancialmente opuestas y, en cierto sentido, complementarias.

Según Todorov, lo fantástico se define como "la vacilación experimentada por un ser que no conoce más que las leyes naturales, frente a un acontecimiento aparentemente sobrenatural"2. El filósofo búlgaro establece que esta vacilación debe afectar en primer término al lector o espectador antes que al personaje, pues "es necesario que el texto obligue al lector a considerar el mundo de los personajes como un mundo de personas reales, y a vacilar entre una explicación natural y una explicación sobrenatural de los acontecimientos evocados"3. La concepción fantástica de Nikolajeva, en cambio, se apoya en la naturaleza del universo diegético como criterio fundamental -y no en el lector o espectador-, y apunta que resulta imprescindible la presencia de un elemento maravilloso que provoque el asombro de los protagonistas: la especificidad de lo fantástico, explica, se identifica con "la presencia de la magia, es decir, de seres y acontecimientos mágicos, en un mundo realista alterno, con el sentido de lo inexplicable, de la maravilla, y con las violaciones de las leyes naturales".

Esta concepción de fantasía propuesta por Nikolajeva coincide con las posturas de Mathews y Manlove, y se fundan en los postulados fantásticos expresados por Tolkien en su ensayo "Sobre los cuentos de hadas" 5 . En este trabajo se sigue esta postura pues, además de la coherencia de su exposición y los avales científicos que la preceden, proporciona un concepto intradiegético idóneo para el análisis narrativo de mundos ordinarios y extraordinarios. Los cuatro autores coinciden en la experimentación de lo imposible, en cuanto sobrenatural o maravilloso, como rasgo que permite identificar los argumentos, situaciones y personajes fantásticos.

Según Nikolajeva, esta experimentación puede darse en dos tipos de universos. En primer lugar, en un esquema de "mundos secundarios", que Tolkien ${ }^{6}$ identifica con universos herméticos extraordinarios a los que se accede desde nuestro "mundo primario", o mundo real, a través de un umbral determinado. En segundo lugar, en un esquema de "mundos implicados" o mundos primarios en los que se produce una intrusión del elemento maravilloso, casi siempre como consecuencia de la irrupción de agentes fantásticos que rompen la vida rutinaria de personajes ordinarios ${ }^{7}$. Este esquema de universo fantástico es

\footnotetext{
${ }^{2}$ Todorov, Tzvetan. Introducción a la literatura fantástica. Buenos Aires: Editorial Tiempo Contemporáneo, 1972, p. 34.

${ }^{3}$ Ibid., p. 44.

${ }^{4}$ Nikolajeva, Maria. The Magic Code. The Use of Magical Patterns in Fantasy for Children, Almqvist \& Wiksell International, Estocolmo, 1988, p. 12.

${ }^{5}$ Cfr. Mathews, Richard, Fantasy. The Liberation of Imagination, Londres: Routledge, 2002, Manlove, C. Modern Fantasy: Five Studies. Cambridge, Mass.: Cambridge University Press, 1975, y Tolkien, J.R.R., "Sobre los cuentos de hadas", en Árbol y hoja, Barcelona: Minotauro, 1994.

${ }^{6}$ Tolkien, op. cit., p. 49.

${ }^{7}$ Nikolajeva, op. cit., p. 88.
} 
precisamente el empleado por Shyamalan en sus cuatro guiones mencionados: en todos ellos se presentan protagonistas del mundo ordinario -psicólogo infantil, un agente de seguridad, un padre de familia y el mantenedor de un vecindario- que experimentan lo maravilloso como algo insólito en su experiencia cotidiana: un paciente que ve muertos, el descubrimiento de la propia invulnerabilidad, la llegada de extraterrestres y el hallazgo de una ninfa en la piscina comunitaria.

\section{Fantasía suburbana. Influencias de Steven Spielberg}

El ámbito hogareño como marco de tramas fantásticas constituye la clave principal para la construcción de universos diegéticos en el cine de Shyamalan. A imitación de Spielberg, uno de sus principales directores de referencia, esto se traduce en el uso del esquema de mundos implicados en sus guiones. "El sexto sentido", "El protegido", "Señales" y "La joven del agua" ofrecen un patrón dramático similar: unos protagonistas pertenecientes al mundo primario asisten a la intrusión de lo maravilloso dentro de su ámbito ordinario, al tiempo que se ven obligados a explorarlo y a redescubrirlo desde una nueva perspectiva que cambia sus vidas.

Durante las filmaciones de "Encuentros en la Tercera Fase" (1978) y "E.T. El Extraterrestre" (1982), Spielberg orientó los recursos de fotografía y diseño de producción hacia la construcción de atmósferas hogareñas de clase media americana, netamente suburbanas, con objeto de subrayar la improbabilidad de un suceso extraordinario o fantástico en semejantes escenarios. A propósito del rodaje de "Encuentros", el director explica: "Trataba de crear un tipo de atmósfera muy diferente de lo que la gente común considera como el marco fantástico ideal para un primer encuentro (...) Me encanta colocar el cosmos junto al realismo del suburbio. Me encanta usar cualquier cosa que sea contraria a lo que estamos acostumbrados. Era esencial que una película de este tipo estuviera centrada aquí, en la Tierra. Tiene lugar en el jardín trasero de tu casa. Debes creer primero en la Tierra para creer después en los platillos volantes"8.

Es fácil identificar esta realidad hogareña en las familias de Cole y de Dunn en "El sexto sentido", "El protegido" y "Señales": en ellas, la cocina a menudo parece la localización ideal para un suceso, y las habitaciones infantiles muestran un atrezzo familiar para el espectador. En este sentido, estas declaraciones de Spielberg sobre el diseño artístico en "E.T." podrían aplicarse a los relatos fantásticos de Shyamalan, en los que también se crean las atmósferas propias de mundos implicados: "Era muy importante que cualquiera que viera la película creyera realmente que 'E.T.' podría aparecer en el jardín trasero de su casa, entrar en sus hogares y visitar a sus hijos (...) Trabajé muy duro para añadir un poco de verdad urbana o suburbana sobre las imágenes de fantasía".

\footnotetext{
${ }^{8}$ Crawley, Tony. The Steven Spielberg Story: The Man behind The Movies. Nueva York: Quill Press, 1983, p. 57.

${ }^{9}$ Turner, George E. "Steven Spielberg and E.T., The Extraterrestrial", American Cinematographer, enero de 1983, p. 81.
} 
Shyamalan, que siempre ha reconocido el estímulo de Spielberg -en especial, "E.T."como narrador de historias ${ }^{10}$, toma esta irrupción de lo fantástico dentro del ámbito hogareño ordinario para hablar de los misterios más profundos, pero también de los asuntos más prosaicos, que afectan a las familias y a las personas corrientes. "Para mí argumenta el director- los asuntos sobrenaturales son metáforas de la historia humana. [Todas ellas] sirven como instrumentos para examinar a las personas y averiguar de qué están hechas, para instarles a decir lo que necesitan decir a sus seres queridos (...). Los filmes sobrenaturales suelen incluir un elemento revelador al comienzo, un guiño que advierte 'nada de esto es real'. Yo intento eliminar ese guiño"'l.

En los relatos de ambos directores se advierte también un segundo rasgo común, consistente en la fusión de las antiguas leyendas y de los cuentos de hadas con la experiencia cotidiana de personajes corrientes envueltos en situaciones extraordinarias. En el cine de Spielberg encontramos agentes fantásticos como E.T., los alienígenas de "Encuentros en la Tercera Fase" o el propio David, el mecha ${ }^{12}$ infantil de "I.A." (2001), que a su vez se inspiran en los arquetipos feéricos ${ }^{13}$ de Peter Pan, el Hada Azul y Pinocho, así como en otros personajes y conflictos presentes en la novela de Barrie, en el cuento de Collodi o en la aventura de Dorothy en "El Mago de Oz". En el cine de Shyamalan, por otro lado, podemos apreciar "El sexto sentido" como un moderno cuento de fantasmas; "El protegido" interpreta el mundo ordinario urbano desde la óptica peculiar del cómic; en "Señales", el entorno rural se transforma en el escenario de una invasión extraterrestre; y en "La joven del agua", una comunidad de vecinos de Filadelfia afronta el rescate de un personaje mágico según la lógica del cuento de hadas.

Tanto en el cine de Spielberg como en los guiones de Shyamalan se aprecian elementos y claves comunes que nos permiten hablar de una sintonía, de un estilo y de una continuidad en la evolución cinematográfica de la fantasía de aventuras. Esta paridad se concreta en otros cuatro rasgos distintivos, derivados de los dos elementos comunes ya mencionados -apoyo en el patrón fantástico de mundos implicados e inspiración en cuentos de hadas-, y que resultan útiles como criterios de análisis del cine fantástico de Shyamalan. En primer lugar, la irrupción del elemento maravilloso en ámbitos hogareños en crisis. Además, el uso de la aventura como revulsivo para la búsqueda de la identidad de los protagonistas. En tercer lugar, la concesión de un estatus privilegiado de los personajes infantiles, que les permite sintonizar con elementos y personajes maravillosos. Y finalmente, la superación de las separaciones entre personajes tras la asunción de una nueva visión del mundo, propiciada por la aventura.

\footnotetext{
${ }^{10}$ Cfr. Aresté, José María, "M. Night Shyamalan. El nuevo mago del suspense", en Breve Encuentro. Estudios sobre veinte directores de cine contemporáneo, Madrid: Dossat, 2003.

11 "Going around in Circles", Film Review, septiembre de 2002, n. 622. Londres: Visual Imagination, p. 43.

${ }^{12}$ En ciencia ficción, robot muy humanizado.

${ }^{13}$ Raza humanoide.
} 


\section{3. "El sexto sentido" (1999)}

"El sexto sentido" es un cuento de fantasmas protagonizado por un niño llamado Cole que posee la insólita capacidad de ver muertos aunque, como expresaba el leitmotiv de la película, "no todo don es una bendición" ("not every gift is a blessing"). Durante el primer acto del guión la acción corresponde a una trama de rescate, la curación de un pequeño enfermo mental por parte del psicólogo infantil Malcolm Crowe, si bien Cole guarda un secreto que se niega a revelar: este factor complica el objetivo de rescate con la resolución de un enigma. Durante su primer encuentro con Malcolm, Cole pronuncia unas misteriosas palabras en latín, "de profundis clamo ad Te Domine!", que el psicólogo identifica más tarde con el salmo 130, ("¡Desde los abismos te invoco, Señor!"). La referencia al salmo constituye una anticipación del primer giro del guión, en que Cole revela a Malcolm su terrible secreto. A partir de ese momento, la curación del niño pasa a convertirse en un rescate sobrenatural, pues Cole se encuentra prisionero en el mundo de los muertos y clama por su salvación.

Mediante la introducción de este elemento maravilloso -la percepción de fantasmas-, el guión abandona el género de lo misterioso para inscribirse en el fantástico. El giro mencionado tiene lugar durante la conversación que mantienen niño y adulto en el hospital, en la que se desvela el secreto de Cole acerca de sus visiones. Con el cierre del primer acto del guión, la trama argumental queda definitivamente encauzada y el género se define como fantasía de aventuras. Por otra parte, el elemento aventurero aparece en el guión a través de la progresiva exploración del mundo extraordinario por parte del psicólogo. Se trata de un periplo en el que no faltarán las dudas de fe y que, cumplida la misión, concluirá con la autorevelación de Malcolm como uno de los muertos que visitan a Cole.

En el planteamiento, los mundos ordinarios de Cole y Malcolm vienen marcados por la separación. En el hogar del psicólogo, los dos esposos aparecen distanciados hasta el punto de que no existe comunicación. Ya en el arranque del guión, durante la escena en que celebran su condecoración por el ayuntamiento de Filadelfia, Anna reprocha a su esposo la relegación de que ha sido objeto en favor de sus pacientes infantiles. A medida que Malcolm se introduzca en el caso de Cole, la fractura familiar se hará todavía más aguda.

El mundo ordinario de Cole también presenta un hogar en crisis. Como Elliott, Cole también acusa la ausencia de su padre, resultado de un divorcio, y mantiene un secreto ante los adultos. Si el protagonista de "E.T." oculta ante Mary la presencia del intruso extraterrestre en el hogar, Cole hace otro tanto ante su madre, Lynn. Sin embargo, a diferencia de lo que sucede en la película de Spielberg, este secreto crea una tensión agobiante en el hogar y provoca el sufrimiento de Lynn, impotente ante el dolor que aqueja a su hijo. Además, la incomunicación se extiende también al exterior del hogar, pues el muchacho sufre bullying en el colegio. 


\subsection{Purificación y desvalimiento. Sintonía infantil con lo maravilloso}

La escena de la revelación ("veo muertos") resulta de importancia capital para la estructura del relato pues, además de reforzar la trama de rescate y enigma, y define las metas interiores de ambos protagonistas y encauza su relación maestro-discípulo.

En esta escena Malcolm relata a Cole la historia de su tristeza, le confía su sentimiento de culpabilidad tras el fracaso previo con un paciente -un caso muy similar al actual-, así como su propia meta interior: piensa que, si consigue ayudar a este nuevo chico, sería como ayudar al anterior. El conflicto del psicólogo es propio de personajes heridos que, a través de una trama de rescate, consiguen purificar una culpa del pasado. Según la clasificación de tramas mentales propuesta por Tobías ${ }^{14}$, se trataría de un tipo de ascenso moral del personaje tras la resolución de un conflicto interno, marcado en este caso por la culpa y el remordimiento.

La sinceridad del psicólogo es correspondida por Cole con la revelación de su secreto: en ocasiones, el niño ve muertos que no saben que lo están, que ven lo que quieren ver. Escenas atrás, el niño ha dado una clave sobre su propio conflicto interno cuando confía a Malcolm lo que no desea: tener miedo. Así como la tristeza del adulto ha causado un problema de comunicación con su esposa Anna, el secreto de Cole y su temor a revelarlo ha provocado a su vez un problema idéntico con su madre, Lynn, y con los amigos del entorno. Malcolm y Cole son dos personajes aislados que viven incomunicados, y entre niño y adulto se establecerá una conexión solidaria.

La historia interior de Cole alcanza su clímax particular con su propia curación, tras decidirse a ayudar al espíritu de una niña llamada Kyra. El muchacho comprende que, para vencer el miedo, es preciso afrontar las visitas de unos espectros que acuden a él porque necesitan su ayuda. Se trata también de una historia de ascenso moral, pero esta vez no parte del deseo de purificación sino de la superación del desvalimiento. La trama interior de Cole es propia de personajes débiles que, si bien son despreciados por aquellos que compiten o coinciden con ellos, su superioridad moral termina por imponerse de modo triunfal.

La segunda obra teatral, representada en el desenlace del guión, pone de manifiesto esta idea: Cole representa en esta ocasión el papel principal, nada menos que de Rey Arturo. Los mismos que le rechazaban como un freak contemplan ahora cómo Cole extrae Excálibur del yunque y es ensalzado como rey. Como Arturo, el pequeño protagonista de "El sexto sentido" es un muchacho que no alcanza los doce años y ha sido relegado al último puesto de la comunidad. Sin embargo, la leyenda es clara: sólo el puro de corazón podrá extraer la espada. Tras decidirse a ayudar a los espíritus, Cole cumple la divisa de

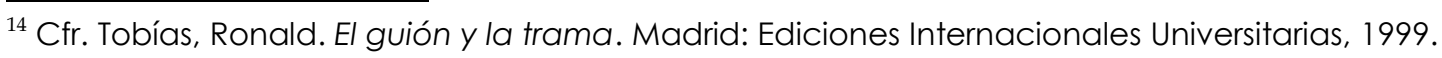


los héroes con su valor: proteger y servir. De ahí la apoteosis en forma de representación infantil con que Shyamalan relata la curación de Cole, objeto externo y clímax de su guión.

A propósito de este desenlace, Harty comenta así el paralelismo entre las parejas ColeMalcolm y Arturo-Merlín: "Cole se ve en el doble papel de Merlín y de rey Arturo [...] Además, también establece una conexión con el pasado y el futuro desde el momento en que se decide a ayudar a los muertos, hechizados por sus propias historias anteriores, y emplea esta habilidad de comunicarse con el pasado para resolver su propio futuro, el de su madre e incluso el de Malcolm, que en principio representa el papel de Merlín, de guía sobrenatural, y ayuda a Cole a asumir el distinguido papel que es llamado a representar"15.

De manera paradójica, la subtrama maestro-discípulo que caracteriza la relación entre niño y adulto se invierte hacia el final del guión, pues el niño proporciona al adulto la clave para comunicarse con Anna y comprender su propia y extraordinaria situación. Para Shyamalan, la película muestra que la superación del miedo, auténtica barrera para la comunicación "ya sea entre un doctor y un paciente, un marido y su esposa, una madre y un hijo, o entre nosotros mismos y los seres queridos que han fallecido. Como sabemos, la incomunicación o la reserva de secretos frente a aquellos a quienes amamos pueden destruir matrimonios, carreras, familias e incluso vidas. Eso en sí mismo es aterrador"16.

La incredulidad de Malcolm contrasta con la especial capacidad de Cole para captar la dimensión extraordinaria del mundo, y este factor nos remite de nuevo a Spielberg. Para el director de "E.T.", la fe infantil en la fantasía responde a una habilidad singular que enfrenta el ámbito de la niñez con el ámbito adulto. Shyamalan presenta a dos personajes inadaptados a la realidad que les rodea, incomunicados con su entorno, tristes, aislados y frustrados. Cole y Malcolm, niño y adulto, no terminan de encontrar su lugar en el mundo: un tema fundamental en el cine del director. Ejerciendo de maestros y discípulos mutuos, los dos protagonistas consiguen entender el sentido de una realidad dolorosa. Cole necesita redescubrir la realidad que le rodea y encontrar un sentido a su insólito don. Con su consagración heroica y la victoria sobre el miedo, el niño da un paso hacia la madurez. Malcolm, por su parte, añora el equilibrio vital perdido. Purificada la herida abierta por Vincent, el psicólogo recupera la comunicación con su esposa, pero también redescubre su identidad de modo impactante y comprende que debía saldar una cuenta pendiente antes de abandonar el mundo definitivamente.

\section{4. "El protegido" (2001)}

En su segunda fantasía de aventuras, el director se basa en los arquetipos del cómic para narrar una historia de superhéroes y supervillanos, con poderes y debilidades complementarios, dentro del marco suburbano de clase media norteamericana. En esta

\footnotetext{
${ }^{15}$ Harty, Kevin J. "An Overview", en Cinema Arthuriane, Jefferson: McFarland \& Company Inc., 2001, pp. $28-29$.

${ }^{16}$ Entrevista con M. Night Shyamalan. The Sixth Sense, pressbook, Buena Vista, 1999.
} 
ocasión, un guardia de seguridad llamado David Dunn llega a descubrir su identidad de superhéroe invulnerable o "irrompible" ("Unbreakable" es el título original de la producción), tras salir completamente ileso de un accidente ferroviario donde la totalidad de los pasajeros ha perecido.

Desde el punto de vista estructural, "El protegido" está construido sobre una doble trama de enigma, pues David intenta resolver el misterio de su resistencia física y, por extensión, de su propia existencia. Al mismo tiempo, el mundo que rodea al protagonista ha comenzado a desmoronarse: su relación con Audrey, su esposa, se encuentra al borde de la ruptura y la tristeza se ha convertido en la tónica de cada mañana. Al objeto externo de David, la resolución de un enigma, aparece unida su meta interior desde el planteamiento de la historia: la superación de la tristeza, que sólo desaparecerá cuando encuentre su lugar en el mundo.

La revelación de los poderes de David se inicia tras el accidente de tren, cuando un desconocido llamado Elijah Price se interese en su caso. Así como Cole representa los papeles de oráculo y sabio anciano de Malcolm, el personaje de Elijah adopta esta doble función respecto a David. Tras dejar una tarjeta con la pregunta "¿cuántos días de su vida ha estado enfermo", el guardia de seguridad le visita junto a su hijo Joseph en la galería artística que regenta, un local decorado con gusto sofisticado donde se exponen dibujos de cómic. Durante el primer diálogo que mantienen, Shyamalan establece la importancia de los relatos populares y su relación con los misterios en torno al hombre.

A espaldas de Elijah, enfermo de osteogénesis, se alza la representación de un jeroglífico egipcio en piedra, símbolo de un tema habitual en el cine de Shyamalan: la realidad codificada. Llegados a esta escena, el director ha unido de nuevo de nuevo el misterio de la propia identidad con el sentido de la vida, un tema recurrente: por una parte, Elijah se ha puesto en contacto con David movido por su deseo de revelar su condición sobrehumana; por otro lado, la incomprensión de un mundo cifrado aparece vinculada a la tristeza.

El guardia de seguridad carece de la clave adecuada para entender el mundo que le rodea, y este hecho ha terminado por levantar una barrera entre los dos esposos que introduce otro tema habitual en Spielberg: la separación. En este sentido, el desarrollo de la subtrama afectiva David-Audrey discurre en paralelo con la relación Malcolm-Anna, ambas basadas en un conflicto marcado por la incomunicación. Ya en la escena de presentación del protagonista, durante el viaje en tren, se muestra cómo David intenta concertar una cita con una atractiva pasajera, tras desprenderse de su anillo de casado. La situación, que concluye con el rechazo inmediato de la mujer, ha sido observada por una niña que viaja en el asiento delantero y que, en el inicio de la escena, contemplaba simpáticamente a David cabeza abajo. 


\subsection{La mirada infantil}

En esta escena de presentación, Shyamalan hace un énfasis en el modo de contemplar la vida desde el punto de vista infantil. Tras el intento frustrado de David con la joven, su mirada se cruza con la de la niña y se pone de manifiesto un contraste impactante entre la inocencia y la culpa, entre el mundo de la niñez y el mundo de los adultos. Por otro lado, en el segundo encuentro de David y Elijah, el director de la galería insiste en la verdad maravillosa que se oculta tras la apariencia vulgar de la realidad: "Vivimos tiempos mediocres. La gente no acepta la posibilidad de los sucesos extraordinarios. ¿̇s usted una persona de mente abierta?" Al sembrar la duda en David, Elijah le ha iniciado en una instrucción peligrosa que consiste, fundamentalmente, en aprender a mirar la realidad con otros ojos. Con ojos infantiles.

En "El protegido", Shyamalan hace numerosos énfasis sobre el modo de contemplar la realidad en su dimensión más profunda. Esta capacidad aparece subrayada, por primera vez, en la escena que acabamos de mencionar. Minutos más tarde, Joseph hace zapping en su casa cabeza abajo -como la niña del tren-y ve en la televisión los restos del convoy donde viajaba su padre. Este personaje infantil resulta fundamental para la autorevelación de David. A diferencia del adulto, el niño nunca dudará de los superpoderes de su padre y contribuirá de modo dramático a resolver el enigma que acucia al protagonista. Joseph admira a su padre y le profesa un cariño que contrasta con la frialdad con que se tratan los esposos.

Shyamalan también subraya en "El protegido" las miradas de Elijah, equiparándolo con Joseph en su manera de observar el mundo. Reflejos, imágenes y miradas son un símbolo temático predominante que, además de constituir un recurso estético de realización, manifiestan la reflexión fundamental del director en su historia: revelación, contemplación.

Shyamalan emplea una anagnórisis de identidad en "El protegido" para reforzar el impacto dramático del clímax del guión, que sucede cuando David asume su condición sobrehumana y realice su primera misión. Tras esta autorevelación tiene lugar el desenlace de la subtrama entre esposos, con su reconciliación definitiva, entre padre e hijo. A la mañana siguiente, sobre la mesa del desayuno, David señala a Joseph la portada del diario. En ella destaca el rescate de los pequeños llevado a cabo la noche anterior y aparece el dibujo del héroe anónimo. Joseph apenas puede contener su emoción. Con el clímax de esta segunda subtrama familiar, se restablece la sintonía entre los dos personajes y con ella nace una armonización entre los ámbitos infantil y adulto.

A propósito del contraste con que el director marca estos dos mundos en su cine, Bramwell apunta que Shyamalan entiende la niñez más allá de un simple símbolo de inocencia natural. "Más bien -explica-, sus intuiciones superiores les atormentan y les empujan a desear la inocencia artificial de los adultos. Los niños saben más que los adultos porque pueden imaginar mucho más, pero no poseen la comprensión necesaria para 
manejar esa potencia. Cuando los héroes adultos conocen las extrañas y a veces terribles verdades, sólo entonces los niños pueden ser liberados de su tensión"17.

En el silencioso diálogo de la cocina, marco típico del mundo ordinario suburbano, Shyamalan hace referencia a la misteriosa unión entre lo maravilloso y lo cotidiano desde una perspectiva humana. ¿̇Algo más prosaico que el mantel del desayuno para tratar sobre lo extraordinario? En "El sexto sentido", la primera manifestación de los espíritus sucede en la cocina mientras Cole desayuna. Por otro lado, el secuestro de Barry en Encuentros en la Tercera Fase se produce durante un estallido literal de electrodomésticos. Y, aprovechando la soledad del hogar, E.T. asalta la nevera y protagoniza un contacto fantástico con Elliott, que asiste a una clase de Biología.

El propio Shyamalan se refiere a la transformación de David y al descubrimiento de su identidad como las tramas dramáticas que abren al espectador, dentro del ámbito fantástico de "El protegido", la dimensión cotidiana y humana del relato: "El arco interno del personaje era realmente importante. Viene a ser como un cuarto nivel de escritura. El espectador no suele considerar este nivel, ni siquiera se lo plantea. Pero una vez que entendí que la paz podría transformarle en una persona completa, en un esposo completo, en un padre completo, que este tipo corriente podía alcanzar su equilibrio al término de la película, en especial con su familia, entonces todo comenzó a encajar"18.

\section{5. "Señales" (2002)}

En "El sexto sentido" y "El protegido", Shyamalan sometía a Cole y a David Dunn a una forja épica, de modo que ambos protagonistas llegan a encontrar su lugar en el mundo a través del descubrimiento de su dimensión heroica. En Señales, realizada en 2002, el director se alejaba de los procesos de iniciación para relatar la historia de una crisis de fe desde una perspectiva insólita.

El guión, también escrito por el director, narra la historia de Graham Hess, un pastor episcopaliano de Pennsylvania que ha decidido romper con sus convicciones religiosas tras el fallecimiento de su esposa Colleen en un accidente de automóvil. Sobre este conflicto interno, el guión arranca cuando en los campos de maíz que rodean la casa de campo donde vive aparecen unas extrañas y gigantescas señales geométricas. Al mismo tiempo, por el hogar familiar rondan extrañas criaturas que emiten unos sonidos característicos para comunicarse. La perplejidad del antiguo pastor y de las autoridades contrasta con la opinión de los hijos de Graham, Bo y Morgan, que creen en la procedencia extraterrestre de las marcas y las interpretan como indicadores de una ruta invasora.

\footnotetext{
${ }^{17}$ Bramwell, Austin W. "Children of Night", National Review, 16 de septiembre de 2002, p. 11.

18 Argent, Daniel (2000). "Breaking Down Unbreakable: An Interview with M. Night Shyamalan", Creative Screenwriting, vol. 7, n. 6, septiembre-octubre. Los Ángeles: C.S. Publications, p. 39.
} 
De nuevo, el guión de Señales, basado en el patrón de invasión, trabaja con protagonistas ordinarios y los somete a una aventura fantástica que transcurre dentro del ámbito familiar. Además su estilo nos recuerda a las situaciones extremas experimentadas por personajes que, asediados por fuerzas extrañas, desfilan por los filmes de su director de referencia: es el caso Barry y su madre, Jillian, en "Encuentros en la Tercera Fase", cuyo hogar es invadido por los extraterrestres; de la familia de Carol Ann en "Poltergeist", que se enfrenta a la hostilidad de unos inquilinos de ultratumba; o de Mary, la madre de Elliott en "E.T.", que comprueba con impotencia cómo su casa es abordada por agentes y científicos enfundados en trajes espaciales.

El elemento fantástico es empleado por Shyamalan como catalizador de emociones y experiencias personales, a través de una situación límite. Graham se une así a David y a Malcolm, pues en palabras del director, "descubre su potencial y descubre quién es, así como todo cuanto le rodea (...). Los elementos sobrenaturales o de ciencia ficción (los fantasmas o los extraterrestres) son irrelevantes para mí. Sólo son un telón de fondo. Un hombre que aprende a creer de nuevo. Cree en sí mismo en 'El protegido'. Cree en el amor y cree en sí mismo como médico en 'El sexto sentido', en su trabajo. Esas son las cosas con las que estoy comprometido al mismo tiempo. Cada una es distinta. Y 'Señales' trata básicamente sobre la fe, sobre la creencia en el destino"19.

\subsection{Azar, destino y providencia}

Como advierte su propio director, la lectura profunda de "Señales" sólo puede llevarse a cabo desde el conflicto interno de su protagonista. Al someterlo a una crisis de fe, Shyamalan apunta directamente a uno de sus temas recurrentes: el sentido de la realidad y el descubrimiento del papel que toda persona desempeña en ella. Suerte contra destino. $O$, en términos religiosos, azar contra providencia. En el interior del protagonista encontramos un personaje herido que ha reducido el problema del dolor y de la muerte al sinsentido del azar. En esta ocasión, la crisis de Graham aparece desarrollada y tratada en toda su amplitud, desencadenada por la muerte de Colleen.

A medida que la amenaza contra el hogar se hace más patente, la desesperanza de Graham se manifiesta mediante una mezcla de tristeza y rabia. El accidente de Colleen regresa a su memoria una y otra vez, en forma de flashbacks, avivando el dolor de la pérdida y recordando que el sinsentido de la muerte es la demostración del sinsentido de la vida. Hacia el desenlace de "Señales", los extraterrestres consiguen romper el cerco y penetran en la granja familiar. Graham, Merrill y los chicos se hacen fuertes en el sótano y repelen el asedio. Durante la noche, Morgan sufre un ataque de asma y su vida corre peligro. Es entonces cuando el antiguo pastor se viene abajo y, llevado por la ira, manifiesta su odio contra Dios.

\footnotetext{
${ }^{19}$ Lee, Patrick, "M. Night Shyamalan had a sense that all Signs pointed to Mel Gibson", Science Fiction Weekly, 5 de agosto de 2002, p. 3.
} 
La escena contrasta con un desenlace feliz, que permite a Graham hilar toda la secuencia de casualidades que lo ha desencadenado: Morgan no ha resultado envenenado por el gas del alienígena porque el asma ha cerrado sus vías respiratorias; la obsesión absurda de Bo hacia el sabor raro del agua ha sembrado el hogar de armas antiextraterrestres; y unas palabras finales de Colleen, que parecían fruto del delirio, han permitido a Merrill terminar con la amenaza de manera definitiva.

Estas anticipaciones del guión, las que dan sentido a la resolución, son las auténticas "señales" de la historia: no las que dejaron los extraterrestres sobre el maizal, sino aquellas que a veces pasan inadvertidas en el transcurso de la existencia ordinaria y que, interpretadas adecuadamente, permiten reconstruir una realidad caótica y azarosa. En "Señales", Shyamalan aborda de modo directo el providencialismo propio del género de fantasía de aventuras, y resuelve el dilema azar-plan divino con una historia interior que concluye con el regreso a la primitiva fe.

Como en los dos filmes precedentes, en esta búsqueda del sentido de una realidad incomprensible cobra un papel especial los personajes infantiles. Bo y Morgan comparten con Cole y Joseph una intuición especial para percibir lo extraordinario, al tiempo que sus intervenciones resultan decisivas para que los adultos protagonistas alcancen sus revelaciones. En concreto, Bo realiza la primera intervención anormal en el guión cuando comenta a su padre un sueño premonitorio. Morgan, por su parte, muestra a Graham un libro sobre extraterrestres con una lámina donde aparece una granja, idéntica a la que viven, incendiada por un platillo volante. Pero más allá de sus premoniciones, los dos pequeños (que a diferencia de su padre, conservan la fe) constituyen en sí mismos dos de las señales fundamentales que permitirán la catarsis del adulto.

En esta actitud de los pequeños hermanos, calmada y comprensiva, frente a la desesperación o el miedo de los mayores, encontramos de nuevo una de las notas características de la fantasía en Spielberg: el contraste entre personajes infantiles y adultos. En su análisis sobre "Encuentros en la Tercera Fase", Mott y Saunders se refieren a esta barrera cuando describe la postura del pequeño Barry, el niño de cuatro años que contacta con extraterrestres en su cuarto infantil: "Barry, tranquilamente atraído, contempla el caos: Spielberg emplea esta escena para mostrar la división entre los niños, que aceptan y aman, y los adultos, que se mantienen escépticos. Sólo los adultos parecen atemorizados en la película"20.

Finalmente, de todas las señales proféticas que se manifiestan al término del guión, conviene resaltar la más importante de todas: Colleen. La esposa fallecida, causa de la crisis de fe que afecta a Graham, es al mismo tiempo el principal oráculo que ha impedido la muerte de Morgan. Se cumple así otra de las constantes de los guiones precedentes de Shyamalan, donde el amor entre los dos esposos siempre se encuentra asociado a la esperanza, a la desaparición de la tristeza y al fin de las dudas. Pero en este caso también pone fin a la separación, tema crucial en Spielberg.

${ }^{20}$ Mott, Donald R., y Saunders, Cheryl M. Steven Spielberg. Boston: Twayne Publishers, 1986, p. 60. 


\section{6. "La joven del agua" (2005)}

En "La joven del agua", Shyamalan retornaba a la fantasía de aventuras con un peculiar cuento de hadas. El guión relata la historia de una narf, una ninfa acuática llamada Story, procedente del Mundo Azul, que una noche aparece en la piscina de una comunidad de vecinos de Filadelfia y es acogida por Cleveland Heep, el mantenedor del bloque. La ninfa, perseguida por unas bestias llamadas scrunts que se confunden con la hierba, busca a un escritor denominado "recipiente" para comunicarle un mensaje vital para la felicidad futura de los humanos. Una vez entregado su mensaje, aparecerá un águila gigante, el Gran Eatlon, que la llevará de nuevo a casa. Pero para ello, Story necesita la colaboración de varios vecinos, entre los cuales deben encontrarse un "guardián", un "intérprete", un "sanador" y un "gremio". A la hora de escribir su historia, Shyamalan tenía en su cabeza los estilos de "E.T." y "La princesa prometida", tal como reconoció en una entrevista tras el rodaje ${ }^{21}$. Examinemos las influencias de estas dos particulares fuentes de inspiración surgidas en los 80.

\subsection{La presencia de E.T.}

El personaje de Spielberg puede reconocerse en la concepción de Story, una intrusa benefactora perseguida que encuentra refugio en el hogar de un humano. Como sucedía entre Elliott y E.T., el vínculo entre Cleveland y la narf llega a ser muy estrecho, y esta sintonía estriba en dos cualidades por parte del personaje humano: inocencia infantil y fe en la fantasía.

Cleveland es un adulto bondadoso que ha sufrido la pérdida de su esposa y sus dos hijos, y desde entonces vive inmerso en la soledad y en la tristeza: dos temas recurrentes en Shyamalan. Sin embargo, la disposición de Cleveland para aceptar lo maravilloso resulta vital para el contacto entre los mundos fantástico y ordinario. Esta actitud, netamente infantil, también se manifiesta durante el relato del cuento de la narf, pues Mrs. Choi supera su desconfianza inicial hacia Cleveland cuando compruebe que en el fondo se trata de un adulto con corazón de niño ${ }^{22}$.

La similitud con "E.T." se completa con la muerte y resurrección de Story. La fe de Elliott en la fantasía permitía la resurrección del alienígena: del mismo modo, Cleveland conseguirá curar las heridas mortales ocasionadas a la narf por los scrunts cuando compruebe que su papel en la misión no es de guardián, sino de sanador. La resurrección de Story tiene lugar mientras Cleveland toma en sus brazos el cuerpo de la ninfa y revive su dolor por la pérdida de su familia. Los recuerda, confiesa que veía en sus seres queridos el rostro de

\footnotetext{
${ }^{21}$ Reflections on Lady in the Water. Herzog Cowen Entertainment, 2006.

22 Para la mujer coreana, el relato de la narf es algo más que una leyenda, pues "su abuela le contaba ese cuento como si fuera una oración, como si fuera verdad".
} 
Dios, y su herida interior queda purificada al tiempo que la joven del agua revive de nuevo.

La historia interior de Cleveland se ajusta perfectamente a los personajes de Shyamalan, que consiguen dar sentido la pérdida a través de una aventura que lleva a la contemplación de lo maravilloso. Para Richard Corliss, el director ha fraguado un arquetipo de protagonista épico que carga con una peculiaridad extraordinaria, como si se tratara de un tumor: "Ellos son, figurada o literalmente, muertos andantes, arrancados de sus esposas y niños por algún suceso terrible. Es entonces cuando toman conciencia de su oscura misión. El heroísmo es la cura de la entropía emocional"23.

\subsection{Arquetipos feéricos. Oráculo infantil y análisis adulto}

La mencionada referencia de Shyamalan a "La princesa prometida" en "La joven del agua" se aprecia en la estructura y en el motor dramático del guión. El director deseaba trasladar la lógica y arquetipos del cuento de hadas a una historia que transcurre en un tranquilo vecindario. La comunidad del bloque de viviendas viene a representar nuestro mundo ordinario, integrado por personajes de diferentes razas y culturas: hispanos, orientales, afroamericanos, occidentales y asiáticos. Todos ellos reciben la visita y el mensaje de Story. La narf es protagonista de un olvidado cuento de hadas, y este factor enfatiza la importancia de las historias en la felicidad de los humanos. Para Shyamalan, la mitopoeia, la creación de historias, es la antigua actividad que permite a los hombres avivar sus nostalgias y deseos fundamentales, atisbar en los misterios humanos y redescubrir la maravilla que se esconde en lo cotidiano.

"La joven del agua" intenta reivindicar el valor de los cuentos de hadas mediante una leyenda actual, donde los arquetipos míticos de los géneros fantásticos adoptan el aspecto de personajes del siglo XXI. Así, el "sanador" es un simpático mantenedor de vida gris; el "guardián" que mantiene a raya a los scrunts es un joven culturista hispano llamado Reggie; el "intérprete", un niño afroamericano, Joey Dury, capaz de leer el futuro en las cajas de cereales; y el "gremio", cinco hermanas que sólo hablan español -las hermanas Torres- a las que se unen la hija de Mrs. Choi y la hermana de Vick, el "recipiente".

Vick constituye la clave de la misión de Story, que en esencia consiste en transmitir un mensaje. El recipiente es un escritor que no acaba de decidirse a terminar su última obra, titulada "Un libro de cocina": un compendio de su filosofía política que, además, contiene su particular visión para armonizar el desorden mundial. Cleveland lleva a Vick ante la presencia de Story y el escritor siente cómo su confusión desaparece de pronto y sus ideas se vuelven más claras. La revelación del propio lugar en el mundo, la misión que hace única la existencia del hombre, se pone de relieve tanto en el personaje de Vick como en los demás arquetipos del guión.

${ }^{23}$ Corliss, Richard. "Mr. Shyamalan's Scary Future", en Time, 16 de julio de 2006, p. 70. 
Por otro lado, el arquetipo feérico del oráculo es empleado por Shyamalan para establecer una antítesis entre dos modos de percibir la realidad, que el director establece a través de la oposición entre dos personajes secundarios, Joel y Farber.

El oráculo recibido por Vick presenta una mezcla de dolor y esperanza, de muerte y felicidad. Para Shyamalan, en estos binomios se encuentran los componentes básicos que entrelazan la realidad humana, incomprensible en su apreciación cotidiana pero admirable cuando la vida se interpreta con el código adecuado. En este sentido, el oráculo de Story resulta similar al de la esposa de Graham en "Señales", y hace presente el providencialismo de las fantasías de aventuras. La revelación en los cuentos de hadas se produce a través de la correcta lectura de los sucesos triviales experimentados en el mundo ordinario, algo que también permite la superación de la tristeza en personajes de Spielberg como Elliott, Roy o Peter Banning -el Peter Pan adulto transformado en pirataen "E.T.", "Encuentros" y "Hook" (1991).

Shyamalan también subraya en "La joven del agua", una vez más, que esta peculiar capacidad de contemplación con la mirada adecuada es una habilidad netamente infantil. Como Joseph en "El protegido" o los pequeños Morgan y Bo en "Señales", la misión del intérprete de símbolos en este cuento de hadas corresponde al pequeño Joey Dury. Ante los textos de las cajas de cereales, el niño consigue revelar información vital para concluir con éxito la misión de Story, en especial la identidad del gremio que ayudará a la narf. Mientras Joey descifra los mensajes, se escuchan diversos comentarios sobre la capacidad del niño: "Es alguien que hace algo antiguo en tiempos modernos", "Podría ser alguien que ve pureza donde nosotros vemos mundanidad, que oye la voz de Dios en lo cotidiano", "Es alguien que encuentra significado a lo cotidiano".

En Shyamalan, esta capacidad para reconocer el sentido de las señales en la realidad está relacionado estrechamente con la naturaleza narrativa de la propia vida, del propio acontecer. Para subrayar esta idea, el director establece una oposición entre los oráculos infantil y fantástico por un lado -Joey y Story-, y el personaje del crítico literario y cinematográfico, el señor Farber, que viene a ser un falso oráculo. Farber es un intelectual que, acostumbrado a la rutina de estudiar y clasificar relatos, ha terminado por reducir las historias a simples tramas que se repiten una y otra vez, meros patrones dramáticos desvinculados de la vida. Según Shyamalan, esta consideración contrasta de manera radical con la concepción de la actividad narrativa como creación mitopoética, que proporciona al ser humano las claves para su propia comprensión y, en último término, para alcanzar la felicidad.

\section{Conclusión}

Como en los guiones fantásticos de Spielberg, el mundo ordinario de Shyamalan se establece dentro de un entorno familiar en crisis, de manera que la irrupción del elemento maravilloso termina provocando una especie de catarsis en los protagonistas. Al mismo 
tiempo, la elección del esquema de mundos implicados favorece un impacto entre lo fantástico y lo cotidiano, pretendido por ambos directores.

Tanto Shyamalan como Spielberg establecen una relación directa entre los conflictos dramáticos generados por la aventura, por un lado, y los conflictos derivados de las fracturas familiares, y esta dependencia se hace patente tanto en el planteamiento como en su resolución. Las relaciones problemáticas entre Cole y su madre en "El sexto sentido" o entre David y Audrey en "El protegido" desaparecen tras la resolución de sus respectivas tramas fantásticas; del mismo modo, los protagonistas de "E.T.", "Encuentros" o "Hook" encuentran, tras sus aventuras, la estabilidad y la superación de las separaciones.

Dentro del ámbito de las historias interiores, otra de las similitudes entre Spielberg y Shyamalan consiste en el descubrimiento de la propia identidad como conflicto esencial de los protagonistas. Los personajes de Shyamalan se encuentran a menudo desorientados dentro de su propio mundo, porque no consiguen hallar su lugar en él y porque la realidad se les presenta carente de sentido: en este sentido, la tristeza de Elliott, de Roy Neary o Banning es comparable a la de Cole, Malcolm o Dunn.

Como Spielberg, Shyamalan también concede una importancia especial a los niños en cuanto personajes dotados para captar una dimensión fantástica imperceptible para los adultos. Sin embargo, a diferencia de Spielberg, Shyamalan reserva el protagonismo de sus historias a personajes adultos. Por otro lado, Shyamalan entiende la comprensión de la realidad como el hallazgo del propio lugar en el mundo. Niño y adulto se prestan las claves necesarias para descodificar una realidad dolorosa e incomprensible $y$, en este sentido, niño y adulto también actúan como oráculos que, al modo de los videntes clásicos, revelan sus identidades: la esencia heroica. 


\section{BIBLIOGRAFÍA}

"Going around in Circles", Film Review, n. 622, septiembre (2002), pp. 40-45.

ARESTÉ, José María. "M. Night Shyamalan. El nuevo mago del suspense", en Breve Encuentro. Estudios sobre veinte directores de cine contemporáneo, Dossat, Madrid, 2003.

ARGENT, Daniel, "Breaking Down Unbreakable: An Interview with M. Night Shyamalan", Creative Screenwriting, vol. 7, n. 6, septiembre-octubre (2000), pp. 38-44.

BAMBERGER, Michael. The Man Who Heard Voices: Or How M. Night Shyamalan Risked His Career on a Fairy Tale, Gotham Books, Nueva York, 2006.

BRAMWELL, Austin W. "Children of Night", National Review, 16 de septiembre (2002).

CORLISS, Richard. "Mr. Shyamalan's Scary Future", Time, 16 de julio (2006).

CRAWLEY, Tony. The Steven Spielberg Story: The Man behind The Movies, Quill Press, Nueva York, 1983.

Entrevista con M. Night Shyamalan. The Sixth Sense, pressbook, Buena Vista (1999).

HARTY, Kevin J. "An Overview", en Cinema Arthuriane, Jefferson: McFarland \& Company Inc., 2001.

Lady in the Water. A Bedtime Story. Warner Bros. Entertainment (2006).

LEE, Patrick, "M. Night Shyamalan had a sense that all Signs pointed to Mel Gibson", Science Fiction Weekly, 5 de agosto (2002).

Making of Unbreakable. Touchstone Pictures, Burbank (2001).

MOTT, Donald R., y Cheryl M. Saunders. Steven Spielberg, Twayne Publishers, Boston, 1986.

NIKOLAJEVA, Maria. The Magic Code. The Use of Magical Patterns in Fantasy for Children, Almqvist \& Wiksell International, Estocolmo, 1988.

Reflections on Lady in the Water. Herzog Cowen Entertainment, 2006.

SÁNCHEZ-ESCALONILLA, Antonio. "Fantasía de aventuras: La exploración de universos fantásticos en literatura y cine", Comunicación y Sociedad, vol. XXII, n. 2 (2009), pp. 109137. 
SÁNCHEZ-ESCALONILLA, Antonio. Fantasía de aventuras. Claves creativas en novela y cine, Ariel, Barcelona, 2009.

TODOROV, Tzvetan. Introducción a la literatura fantástica, Editorial Tiempo Contemporáneo, Buenos Aires, 1972.

TOLKIEN, J. R. R. "Sobre los cuentos de hadas", en Árbol y hoja, Minotauro, Barcelona, 1994.

TURNER, George E., "Steven Spielberg and E.T., The Extraterrestrial", American Cinematographer, enero (1983), pp. 